\title{
Kompilasi Buku Cerita Anak sebagai Media Edukasi di Masa Pandemi
}

\author{
Rabendra Yudistira Alamin, Nugrahardi Ramadhani, Nurina Orta, \\ Putri Dwitasari, Didit Prasetyo, dan Naufan Noordyanto \\ Desain Komunikasi Visual, Fakultas Desain Kreatif dan Bisnis Digital, \\ Institut Teknologi Sepuluh Nopember, Surabaya, Indonesia \\ e-mail: rabendrayudistira@gmail.com
}

\begin{abstract}
Abstrak-Pada masa pandemi ini, Satgas Covid-19 Institut Teknologi Sepuluh Nopember (ITS) bekerja sama dengan berbagai pihak terus berupaya memberikan informasi kepada masyarakat dalam rangka sosialisasi dan edukasi terkait penanganan pandemi. Salah satu luaran media yang digunakan oleh Satgas Covid-19 ITS bekerja sama dengan civitas akademika ITS untuk menyasar keluarga dan anakanak adalah adalah buku cerita anak bergambar. Media tersebut dianggap memiliki kelebihan yang mencakup beberapa kriteria komunikasi, sehingga informasi di dalamnya dapat tersampaikan dengan baik melalui pesan berupa narasi dan visual. Diharapkan dengan buku kompilasi cerita anak tersebut, pesan edukasi dapat diserap melalui media yang lebih menarik, interaktif, dan mudah di akses oleh semua lapisan masyarakat.
\end{abstract}

Kata Kunci-kompilasi, buku cerita anak, keluarga, media edukasi, dan masa pandemi.

\begin{abstract}
During the Covid-19 pandemic. The task force of Institut Teknologi Sepuluh Nopember (ITS), in collaboration with various parties, continued to provide information to the public in the context of socializing and educating the handling of the pandemic. One of the external media used by the ITS Covid19 task force in collaboration with the ITS academic community to target families and children is illustrated children's storybooks. The media is considered to have advantages that include several communication criteria so that the information in it can be conveyed properly through messages in the form of narration and visuals. It is hoped that with the compilation of children's stories, educational messages can be absorbed through media that are more interesting, interactive, and easily accessible to all levels of society.
\end{abstract}

Keywords-compilation, children story's book, family, educational media, pandemic period

\section{PENDAHULUAN}

Demografi masyarakat Indonesia yang terdiri dari beragam latar budaya dan tingkat pendidikan, menciptakan tantangan tersendiri dalam upaya sosialisasi dan edukasi. Berdasarkan fenomena tersebut, pada masa pandemi, Satgas Covid-19 ITS membutuhkan strategi sosialisasi dan edukasi yang dapat menyentuh seluruh lapisan masyarakat. Dalam hal ini, pemilihan media menjadi bagian dari strategi komunikasi yang penting agar konten edukasi yang disampaikan menjadi lebih mudah dipahami dan diimplmentasikan oleh target masyarakat yang dituju.

Keluarga dan anak-anak merupakan target yang penting bagi kampanye edukasi penanggulangan Covid-19. Hingga bulan Oktober 2021, korban jiwa anak-anak akibat Covid-19 di Indonesia mencapai angka 1396 jiwa [1]. Sampai dengan 1 April 2020, UNESCO mencatat setidaknya 1,5 miliar anak usia sekolah yang terdampak Covid 19 di 188 negara termasuk 60 jutaan diantaranya ada di negara kita [2]. Sebagai sebuah struktur masyarakat terkecil, keluarga perlu dibekali dengan kesiapan, keterampilan dan pengetahuan yang memadai terkait penanganan pandemi. Disini diperlukan media yang mudah untuk melakukan penetrasi ke dalam semua anggota keluarga, khususnya orang tua dan anak-anak.

Diantara beberapa media edukasi yang dirilis oleh Satgas Covid-19 ITS adalah Buku Cerita Anak. Buku cerita anak dianggap memiliki kelebihan yang mencakup beberapa kriteria komunikasi. Berdasarkan penelitian yang dilakukan oleh Edmunds dan Bauserman, karakteristik buku mempengaruhi minat baca anak-anak [3]. Dalam hal ini anak-anak menikmati cerita-cerita dengan ilustrasi yang baik. Cerita yang mengandung humor membuat mereka merasa senang dan tertawa lepas, sementara cerita yang mengandung sesuatu yang menakutkan membuat mereka penasaran dengan apa yang terjadi berikutnya. Salah satu dukungan psikologis yang disarankan adalah mengajarkan berpikir positif dengan menanamkan harapan-harapan nyata bahwa kondisi akan membaik dengan pola kebiasaan baru [4]. Selain itu karakter generasi post-milenial adalah 'participatory learners' yang cenderung menghimpun informasi dari berbagai sumber. Edukasi tidak lagi hanya berpusat pada pembelajaran formal, melainkan bisa dilakukan dimana saja dan kapan saja [5].

Konten edukasi yang menyasar kepada keluarga dan anak-anak akan didesain sedemikian rupa untuk memenuhi unsur-unsur tersebut. Metode perancangan meliputi perumusan konten, penentuan konsep desain, editorial, pembuatan prototype dan finalisasi format.

\section{METODE}

Penelitian ini menggunakan metode perancangan design and develop. Data pada penelitian ini berupa kajian pustaka tentang pandemi COVID-19. Survei terhadap rancangan dan temuan dari uji coba program yang disusun. Berdasarkan tujuan penelitian dan kebutuhan data, dapat dipakai pendekatan R\&D (research and development) desain model 
3D berupa define, design, and develop [6].

\section{HASIL DAN PEMBAHASAN}

Informasi penting terkait edukasi akan disisipkan ke dalam sebuah buku kompilasi berisi kurang lebih 15 (lima belas) cerita anak, hasil karya mahasiswa Departemen Desain Komunikasi Visual (DKV), Institut Teknologi Sepuluh Nopember (ITS), seperti dapat dilihat pada Gambar 1. Karakter dan environment dalam cerita didesain dengan unsur Indonesia agar target pembaca merasa dekat dengan cerita. Aktivitas yang didasari kasus nyata terbukti membantu siswa memahami konsep yang kompleks dan multidimensional [7].
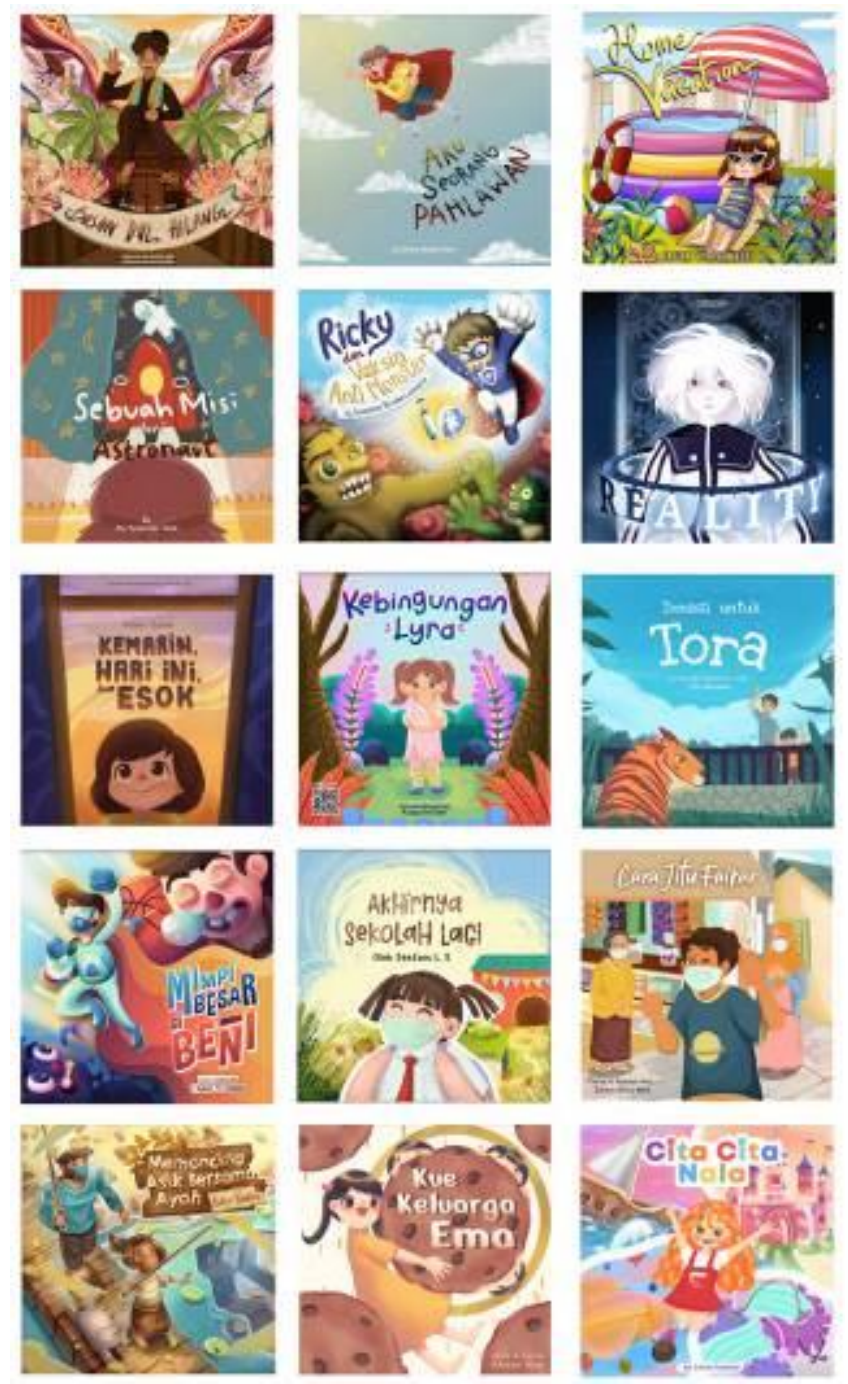

Gambar. 1 Desain sampul dari 15 cerita anak hasil karya mahasiswa DKV ITS.

Berdasarkan timeline atau pembabakan dalam tema pandemi, cerita dalam 15 judul tersebut dapat dipilah menjadi 4 (empat) kategori, sebagai berikut:

1. Permulaan.

Penggambaran awal ketika pandemi mulai datang ke Indonesia dan membawa begitu banyak perubahan ke dalam berbagai sendi kehidupan di masyarakat.

2. Tantangan.

Penggambaran kesulitan dan penderitaan yang dialami oleh sebagian besar masyarakat Indonesia, sekaligus contoh-contoh bagaimana masyarakat bertahan hidup dengan berbagai cara.

3. Penanggulangan.

Penggambaran berbagai upaya yang dilakukan oleh Pemerintah dan segenap lapisan masyarakat. Berbagai kreatifitas dan peluang yang muncul di tengah himpitan dan segala keterbatasan.

4. Harapan.

Penggambaran kehidupan pasca pandemi berahir. Hikmah dari pandemi yang melahirkan berbagai kebiasaan baru yang positif dalam berbagai aspek kehidupan.

Penggambaran keseluruhan cerita adalah melalui sudut pandang anak-anak, dengan latar belakang kehidupan sehari-hari dan keluarga. Metode visual yang digunakan juga menggunakan gaya gambar dengan target market usia 7-10 tahun. Penyajian halaman menggunakan format persegi, dengan penyajian akhir flip spread-sheet.

Tema cerita yang disepakati dalam buku kompilasi ini adalah "Kisah Anak Indonesia di Tengah Pandemi". Penyusunan narasi dari setiap cerita diserahkan kepada masing-masing author, dengan memperhatikan kriteria pembagian kategori yang telah disebutkan. Dengan demikian diharapkan, buku kompilasi akan memiliki varian tema dan cara bertutur yang beragam untuk menghindari kebosanan.

Selanjutnya tim pengbadian masyarakat (abmas) melakukan screening awal untuk redaksional, untuk dilanjutkan ke proses editorial. Proses ini dilakukan bersama tim Satgas COVID-19 Bidang Perubahan Perilaku, dengan melibatkan beberapa psikolog sebagai tim ahli. Tim peneliti menggunakan pedoman karya fiksi yaitu unsur naratif dan unsur sinematik [8]. Unsur naratif berkaitan dengan cerita yang diangkat, dan sinematik berkaitan dengan bagaimana cerita disampaikan melalui bahasa gambar.

Beberapa tantangan yang dihadapi para author dan editor adalah perubahan fenomena dan konten informasi edukasi yang terus berkembang dinamis. Hal ini menyebabkan sebagian konten menjadi kadaluarsa atau tidak lagi relevan, sehingga wajib diganti. Mislakan, cerita yang menggambarkan penyemprotan disinfektan ke jalan raya, dimana belakangan diketahui bahwa tindakan tersebut kurang efektif dalam penanggulangan Covid-19. Adegan tersebut pada akhirnya direvisi menjadi adegan pembangunan beberapa fasilitas cuci tangan di jalan raya dan public space.

Beberapa penyesuaian juga banyak berkaitan dengan penyesuaian antara logika fiksi dengan fakta yang ada dilapangan. Meskipun narasi yang dibuat adalah fiktif, namun cerita yang disampaikan dalam buku kompilasi diharapkan masih realistis dan berpijak pada fakta ilmiah yang terjadi dalam dunia nyata. Tujuannya agar pembaca dapat lebih menghayati cerita karena kejadian-kejadian didalamnya mudah ditemukan disekitar mereka. Seperti halnya media permainan, ketika seseorang menemukan kedekatan dengan kehidupan mereka, maka secara tidak sadar mereka akan lebih dapat berekspresi dan termotivasi untuk menggali pembelajaran berdasarkan peran yang mereka pilih [9]. Bahasa fiksi (film, buku cerita, komik, dan 


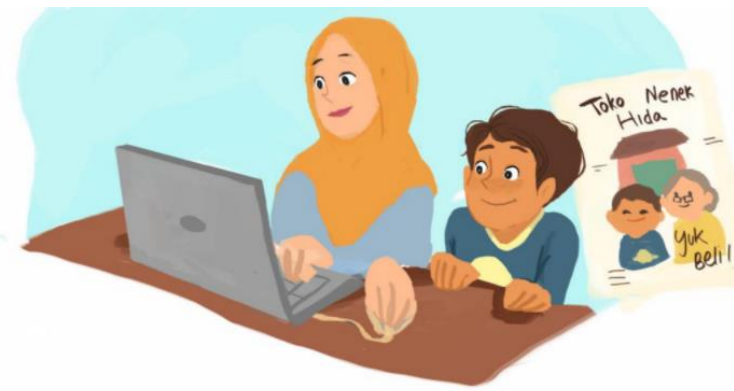

Mama membantu menyebarkan poster buatan Faikar di sosial media. Selain itu, mama juga membantu memberikan sumbangan untuk nenek Hida.

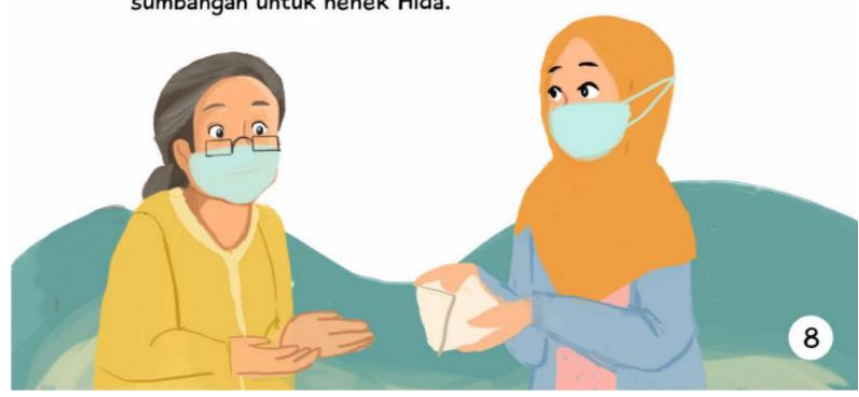

Gambar. 2. Contoh adegan inspiratif pada cerita "Cara Jitu Faikar".

sebagainya) bukanlah bahasa konsep, melainkan bahasa pengalaman. Pemahaman yang ditimbulkannya pun lantar bersifat total, gestalt, melibatkan perasaan, sensasi tubuh, imajinasi dan pikiran sekaligus [10].

Setiap cerita dalam buku kompilasi tersebut wajib memiliki pesan moral dan kebaikan universal. Hal ini bertujuan agar buku tidak hanya berisi muatan edukasi yang sifatnya pratis dan terapan, namun juga menyentuh sisi psikologi atau afektif dari pembacanya. Aspek narasi didesain sedemikian rupa agar dapat memberikan inspirasi dan teladan bagi anak-anak, keluarga dan lingkungan disekitarnya. Contoh dari penerapan nilai-nilai tersebut terletak pada cerita "Cara Jitu Faikar" karya Zahirah Salma Nuha.

Seperti yang ditunjukkan dalam Gambar 2, judul tersebut menceritakan tentang seorang anak yang tergerak untuk membantu toko tetangganya dengan berpromosi melalui media online. Adegan tersebut mengandung pesan moral kepedulian terhadap sesama dan kesetiakawanan sosial. Masyarakat diharapkan berpartisipasi aktif membantu orang terdekat di lingkungannya yang sedang mengalami kesulitan. Pesan serupa juga dapat ditemukan pada beberapa cerita lain. Misalnya pada judul "Donasi untuk Tora" karya Tito Maulana, yaitu cerita tentang seorang anak yang mendonasikan sebagian tabungannya untuk Kebun Binatang demi menyelamatkan seekor harimau didalamnya.

Selain cerita yang menyajikan contoh tindakan nyata, beberapa cerita juga mengangkat penghargaan terhadap profesi tertentu, misalnya Nakes dan Dokter. Terdapat pula beberapa cerita yang menyajikan gambaran kehidupan yang lebih baik pasca pandemi, untuk menumbuhkan optimisme dan harapan bagi pembaca. Contohnya seperti yang tersajikan pada Gambar 3, yaitu cerita berjudul "Kebingungan Lyra" karya Kealyn Din Dalmi. Disana terdapat penggambaran masa depan dimana anak-anak dapat bermain dengan bebas dan gembira di sebuah taman bermain.

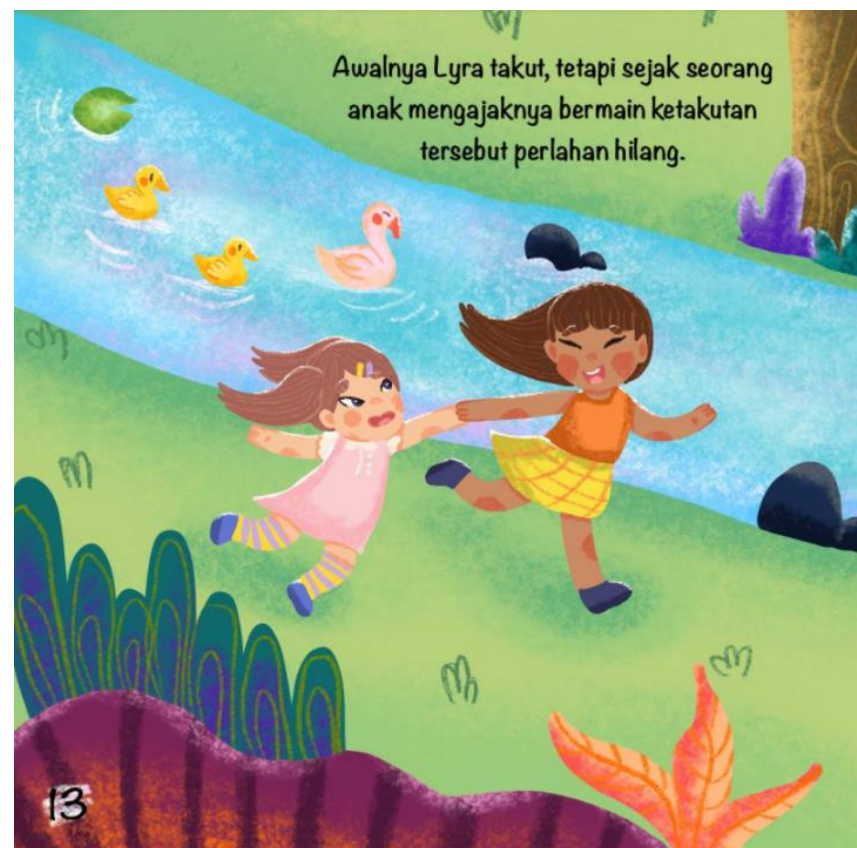

Gambar. 3. Contoh adegan masa depan pada cerita "Kebingungan Lyra".

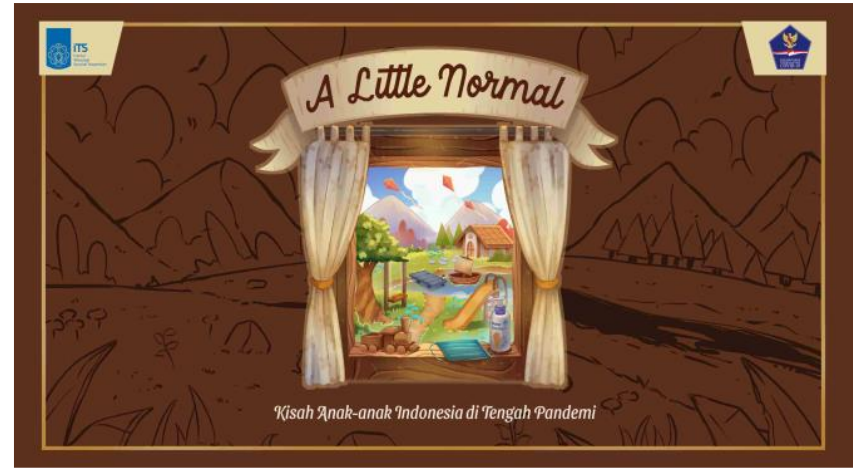

Gambar 4. Konsep cover utama dari buku cerita kompilasi.

Setelah proses editorial selesai dilakukan, berikutnya tim melakukan tahap layouting dan merancang cover dari buku kompilasi. Gambar 4 menampilkan konsep cover terpilih, yaitu sebuah jendela dari dalam rumah, dimana diluar terdapat pemandangan yang merepresentasikan keindahan dan dunia yang dirindukan oleh anak-anak semasa pandemi. Sebagai vocal-point, gambar yang terlihat melalui jendela tersebut sengaja di desain dengan kontras dan berwarna.

Buku kompilasi menggunakan Headline judul "Little Normal" yang secara harfiah dapat diartikan "Sedikit Normal" atau "Normal yang kecil". Judul tersebut secara implisit berkorelasi dengan subjek yang kecil (anak-anak), dan secara generik menggambarkan judul cerita anak yang banyak menggunakan 'little' sebagai kata depan. Disamping itu bisa dimaknai juga dengan; kerinduan dari setiap anak yang harus mengalami masa-masa sulit di tengah pandemi, untuk kembali hidup normal seperti sedia kala.

Selain memuat cerita bergambar, pada buku cerita kompilasi, telah disisipkan beberapa 'Halaman informasi' berisi muatan edukasi terkait pandemi. Halaman ini merupakan bagian buku yang menyajikan informasi terkait pandemi secara eksplisit. Setiap halaman informasi tidak memiliki keterkaitan langsung dengan cerita-cerita anak 


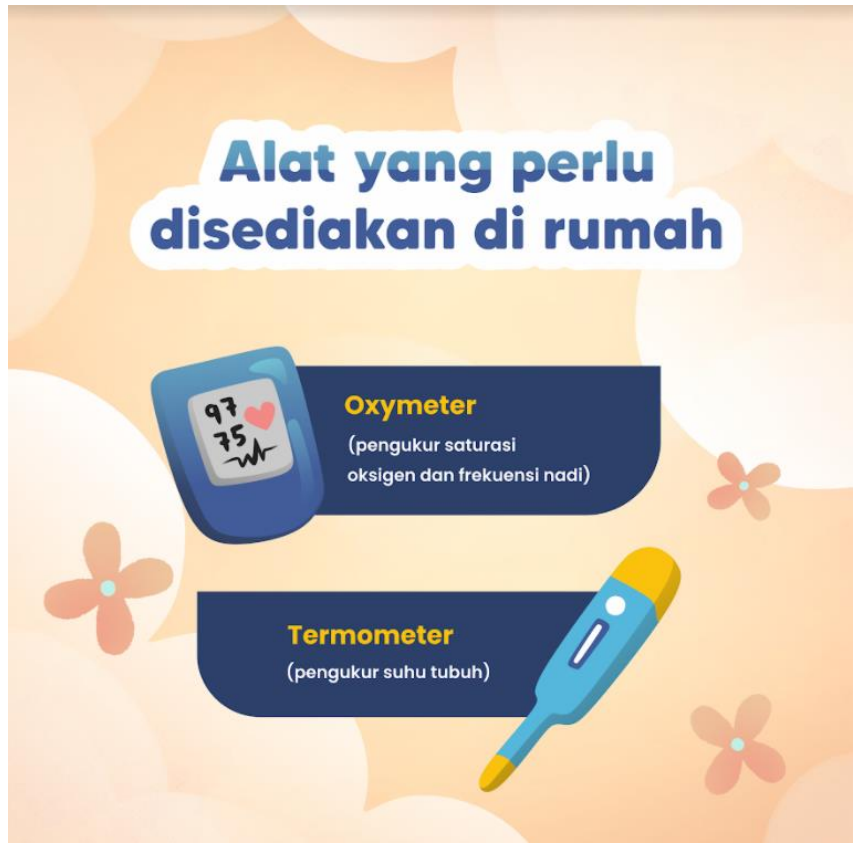

Gambar 5. Sample halaman informasi.

yang disajikan. Kriteria visual pada halaman informasi juga berbeda dari halaman buku cerita, sehingga keberadaannya mudah dideferensiasikan dan mudah ditemukan. Konten pada halaman informasi merujuk pada beberapa sumber dan panduan Satgas Covid-19 dengan proses editorial dan penyesuaian untuk target keluarga dan anak-anak.

Gambar 5 merupakan contoh halaman informasi yang ditempatkan sebagai sisipan pada halaman isi. Peletakan halaman informasi berada di akhir setiap dua judul buku cerita, dengan format landscape.

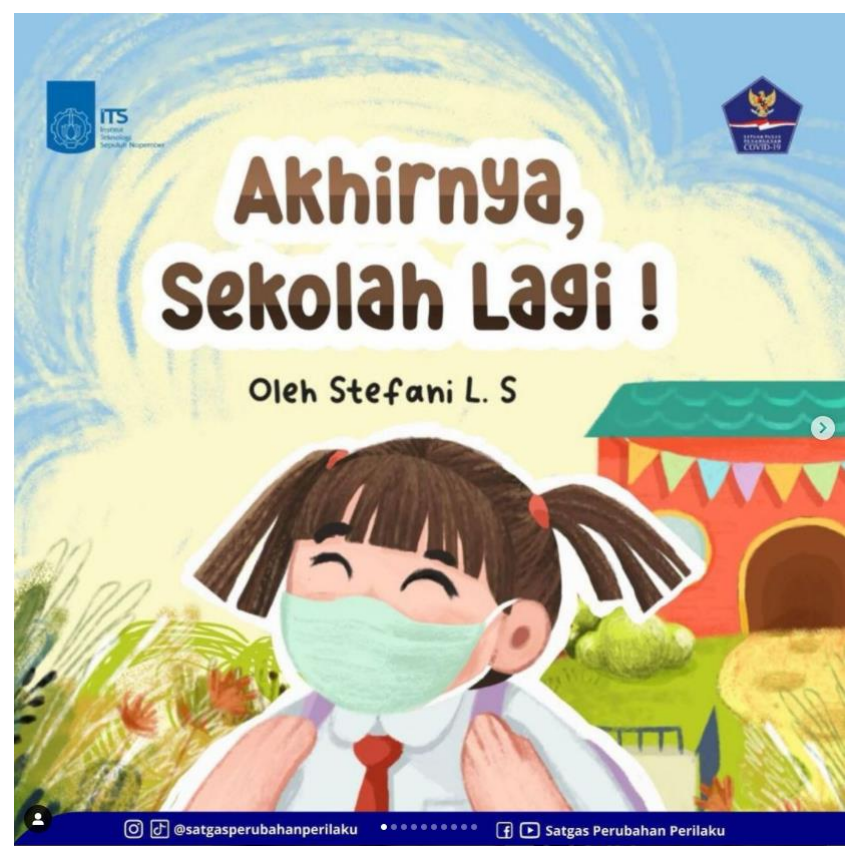

Gambar 6. Sample judul yang dirilis melalui media sosial Instagram satgas perubahan perilaku.

Buku kompilasi cerita anak ini dirilis dalam format digital, agar cakupan distribusinya lebih mudah dan dapat diakses secara luas oleh semua lapisan masyarakat. Distribusi dilakukan oleh tim Satgas Covid-19 bidang
Perubahan Perilaku dengan cara menyebarkan link unduh melalui beberapa platform digital yang sudah dipersiapkan. Masyarakat diharapkan dapat mengunduh buku ini secara gratis dalam ukuran file yang tidak terlalu besar. Selain itu distribusi juga akan melibatkan kerjasama dengan berbagai instansi dan dinas terkait.

Beberapa judul buku dirilis secara terpisah melalui akun sosial media Satgas Covid-19 bidang perubahan perilaku. Hal ini dilakukan dengan pertimbangan bahwa beberapa karya sangat sesuai dirilis bertepatan dengan kebijakan pemerintah di masa pandemi. Contohnya seperti yang tersajikan pada Gambar 6, judul "Akhirnya Sekolah Lagi!" dan "Kemarin, Hari ini dan Esok" dirilis ketika pemerintah menetapkan perkuliahan tatap muka dan hybrid mulai diberlakukan di beberapa daerah pada bulan September 2021. Selanjutnya setiap judul akan dirilis terpisah secara berkala, sesuai dengan kebijakan mitra Satgas-Covid 19 Bidang Perubahan perilaku.

\section{KESIMPULAN/RINGKASAN}

Edukasi pandemi dapat dilakukan melalui berbagai cara, salah satunya adalah media kreatif. Buku kompilasi cerita anak merupakan contoh bahwa sebuah sosialisasi program Pemerintah dapat disampaikan dengan lebih menarik dan menyenangkan. Edukasi melalui buku kompilasi cerita anak tidak hanya mampu menghadirkan informasi yang bersifat praktis dan terapan, namun juga sanggup menyentuh sisi psikologi dari pembacanya. Melalui cerita-cerita yang kreatif dan inspiratif, diharapkan pembaca dapat mengambil hikmah dan mengimplementasikannya. Nilai-nilai yang dapat dipetik dalam buku tersebut diantaranya; harapan, optimisme, disiplin, kesetiakawanan sosial, kemanusiaan, keteguhan hati, cinta tanah air, dan sebagainya.

Meski begitu, media tersebut masih memerlukan dukungan atau support dari media lain untuk dapat melengkapi informasi di dalamnya. Media penunjang dapat berupa aplikasi, video, animasi, maupun poster-poster digital. Diharapkan dengan berbagai alternatif media yang diluncurkan, kampanye edukasi dapat lebih mudah diterima dan membawa dampak yang signifikan, khususnya penanganan pandemi yang berhubungan dengan Perubahan perilaku masyarakat di Indonesia.

\section{UCAPAN TERIMA KASIH}

Tim peneliti menguncapkan terima kasih kepada Pusat Kajian Sustainable Development Goals DRPM-ITS., Mitra Satuan Tugas Penanganan COVID-19-Bidang Perubahan Perilaku, tim penyusun, para author Buku Cerita Anak, dan mahasiswa kelas Ilustrasi Konseptual tahun 2021, serta seluruh pihak yang tidak dapat kami sebutkan satu persatu.

\section{DAFTAR PUSTAKA}

[1] https://data.covid19.go.id. Diakses 11 Oktober 2021

[2] Edmunds, K. M., Bauserman, K. L. (2006). What teachers can learn about reading motivation through conversations with childrren. The Reading Teacher, 59,5. 
Vol. 20, No.2, Oktober 2021, pISSN 1411-3023, eISSN 2580-0264

[3] Panduan Orang Tua Dalam Menghadapi Pembelajaran Tatap Muka, HIMPSI Jawa Timur, September 2021

[4] Aburahma, Mona Hassan. Mohamed, Heba Moustafa.(2015). Educational Games as a Teaching Tool in Pharmacy Curriculum. American Journal ofPharmaceutical Education 2015; 79 (4) Article 59

[5] Setiawan, Adib Rifqi (2021). Pembelajaran Literasi Finansial Untuk Tingkat Dasar. Alobatnic Research Society (ARS); 4 Februari 2021.

[6] Sierra, J., \& Rodríguez-Conde, M.-J. (2021). The Microfinance Game: Experiencing the dynamics of financial inclusion in developing contexts. The International Journal of Management Education, 19(3), 100540.

[7] Pratista, H. 2008. Memahami Film. Yogyakarta: Homerian Pustaka

[8] Kusuma, G. P., Wigati, E. K., Utomo, Y., \& Putera Suryapranata, L. K. (2018). Analysis of gamification models in education using MDA framework. Procedia Computer Science, 135, 385-392.

Barthes, R. 2007. Membedah Mitos-mitos Budaya Massa: Semiotika atau Sosiologi Tanda, Simbol, dan Representasi. Yogyakarta: Jalasutra 